\title{
ARTE NO ENSINO FUNDAMENTAL E SUAS CONTRIBUIÇÕES PARA UMA APRENDIZAGEM SIGNIFICATIVA
}

\author{
Juliano Jesus Pereira
}

\section{RESUMO}

O presente artigo tem o objetivo de apresentar um estudo sobre o papel da Arte nas escolas e promover reflexões acerca da integração das atividades artísticas no currículo escolar, conhecer e compreender a atuação dos profissionais que ministram aulas da arte no ensino fundamental, já que muitos professores ministram aulas de arte sem ter uma formação específica, tornando muitas vezes as aulas monótonas e cansativas, dessa forma subtende-se que não é dado a devida importância a essa área de conhecimento, deixando-a geralmente em um patamar secundário em relação às outras disciplinas do currículo escolar. É notório que através da arte o educando poderá relacionar-se com o meio social de forma mais prazerosa. Pois já foi constatado através de projetos sociais que visam a integração do indivíduo à sociedade, que a arte têm conseguido afastando muitas crianças e adolescentes do mundo da criminalidade. Levando-os a valorizar e resgatar elementos cultural no meio que esta inserido.

Palavras-chave: Arte. Escolas. Professores. Adolescentes.

\section{INTRODUÇÃO}

O ensino de Arte vem sendo tratada na maioria das escolas brasileiras, como suporte para as demais disciplinas que compõe o quadro curricular, desse modo percebe-se que acaba negando o seu caráter específico já que é considerada uma área do conhecimento humano. Segundo Fusário (1992, p. 16): “que importância é esta que se está dando à Arte e faz com que ela tenha um espaço também na Educação em geral e escolar?" ele propõe que "é de suma importância entender que a arte se constitui de modos específicos da atividade criativa dos seres humanos". Fusari ressalta ainda que a capacidade de criar é intrínseca ao homem, no entanto, verifica que ao longo da história da educação, a arte não esta sendo reconhecida como tal. Dessa forma se faz necessário que o Ensino de Arte seja discutido dentro das especificidades inerentes à sua área, pois, dessa forma sua aprendizagem será muita mais gratificante.

Existem uma série de aspectos relevantes que nos leva a perceber que a Arte na educação merece ser mais discutida na academia pelos acadêmico também pelos professores. Duarte Júnior (1991) classificou a Arte através de três dimensões importantíssimas: a 
sociocultural, onde seu objetivo é de apontar o pensamento artístico valorizando e preservando a cultura de um determinado grupo social; a dimensão currículo-escolar, pois através dela a arte como área específica oportuniza ao o aluno conexões com outras disciplinas do currículo; e a dimensão psicológica, cuja o objetivo é dinamizar a educação em arte com objetivo de promover um pensamento amplo e ter capacidade de fazer com que o indivíduo possa trocar conhecimentos e relacionar-se com outros com intuito de enriquecer a criatividade.

É importante salientar que no Brasil, a Lei de Diretrizes e Bases para a Educação Nacional -LDB no 9.394/96 no Artigo 26, inciso $2^{\circ}$, estabelece a obrigatoriedade do Ensino de Arte na Educação Básica, compreende a Educação Infantil, o Ensino Fundamental e o Ensino Médio, dessa forma houve a legitimação da Arte enquanto Área Curricular.

Os PCNs vem apresentando a Arte como uma das possibilidades de valorização do ser humano por meio de suas diversas formas de manifestação entre a cultura de um povo, no entanto, no contexto atual do ensino, percebe-se que existem vários elementos que compromete o desenvolvimento e até mesmo a a eficácia do que está previsto nos PCNs.

Contudo, constata-se que a Arte traz possibilidades para que o educando possa conviver e se relacionar-se com o meio social de forma mais prazerosa. Deixando o indivíduo longe da criminalidade e fazendo com que o mesmo resgate o valor da cultural no meio em que está inserido.

\section{O ENSINO DE ARTE NO BRASIL}

O ensino de Arte surgiu no Brasil com a chegada dos jesuítas, naquela época a arte tinha o objetivo de ensinar a religião católica e educar os indígenas. Em 1826, o ensino de Arte tornou-se oficial no Brasil, com a criação da Academia Imperial de Belas Artes, vinda da França com a proposta de preparar as pessoas para o trabalho.

No início do século XX, houve grande preocupação com o ensino de Arte pois, a mesma se resumia ao ensino de desenho, onde era valorizada apenas a cópia. Nesse período a educação ainda era vista como um ensino autoritário, somente o professor era dono do saber. O ensino de Arte tinha como proposta a cópia fiel de desenhos, ensinando o mesmo para toda a turma.

Em 1930, o ensino de Arte começa a ganhar espaço no Brasil, surgindo escolas para crianças e adolescentes. Porém, com o período de ditadura do presidente vigente Getúlio 
Vargas (1882-1954), a educação em geral se viu descuidada e com ela o ensino de Arte foi posto à margem das demais disciplinas. Dessa forma em 1940 foram criadas as "Escolinhas de Arte" projeto educacional concebido por vários artistas da época.

As propostas das "Escolinhas de Arte" era o ensino baseado na livre expressão, considerando premissas da psicologia e utilizando para isso materiais como: lápis, pincel, tinta, argila entre outros, de forma que cada um tinha a liberdade para expressar a sua arte conforme sua vontade.

Barbosa (1984, p. 15), sobre as Escolinhas de Arte, afirma que:

As práticas das escolinhas começaram a se fazer presentes na escola primária e secundária por meio das classes experimentais criadas no Brasil depois de 1958. Convênios foram estabelecidos com instituições privadas para treinar professores, chegando mesmo as Escolinhas a serem uma espécie de consultores de arte-educação para o sistema escolar público. Até1973 as Escolinhas eram a única instituição permanente para treinar o arte educador.

A partir da lei nº4024/1961- LDB que as discussões e os estudos sobre currículo se desenvolveram com maior eficiência. Na década de 1970, foi criada a lei 5692/71, finalmente o ensino de Arte foi inserido no currículo do Ensino Fundamental, com a nomenclatura de "Educação Artística", a mesma era considerada apenas uma "atividade educativa" e não uma disciplina.

De acordo com esta lei, o professor deveria abordar neste ensino os conteúdos de Música, Teatro, Dança e Artes Plásticas, nos cursos de $1^{\circ}$ e $2^{\circ}$ graus (atualmente ensino fundamental e ensino médio). A proposta de trabalho designada para este professor, nesta época, é que ele deveria dominar todas essas expressões artísticas. Apesar do ensino de Arte ser obrigatório, os professores que ministravam esse ensino não tinham uma formação que contemplasse essas várias vertentes artísticas.

É importante salientar que, com a implantação da Educação Artística foi possível abrir um novo espaço para o ensino de Arte, no entanto, percebeu-se que o sistema educacional vinha enfrentando dificuldades em relação a uma melhor compreensão da utilização de metodologias que abordassem teoria e a prática no ensino e aprendizagem dessa nova área de conhecimento.

Os professores tinham como base os "Guias Curriculares", que objetivava orientar o trabalho em sala de aula, mas sem uma abordagem mais sistemática em relação a metodologias que poderiam auxiliar e melhor orientar a atuação dos professores de Arte nas escolas. 
Em 20 de dezembro de 1996, foi implantado da nova Lei de Diretrizes e Bases da Educação Nacional (LDBN), lei no 9394, nesse momento surge uma nova concepção de educação, incluindo o ensino de Arte no contexto escolar. Com a nova LDB, a "Educação Artística", passa a ser considerada "disciplina", Esta nova lei propõe que esta disciplina atenda todos os níveis de Educação Básica, também como intuito de desenvolver e promover a cultura. Atuação dos professores de Arte nas escolas. A partir de então, também o ensino de Arte passa a se tornar uma disciplina, como as demais do currículo escolar e reconhecida como área do conhecimento.

\section{A ARTE FUNDAMENTADA ATRAVÉS DA NA LEGISLAÇÃO BRASILEIRA PARA EDUCAÇÃO}

A instituição escolar nada mais é do que o lugar destinado ao planejamento, produção e execução de trabalhos relacionados ao conhecimento e o desenvolvimento das atividades educacionais. É importante ressaltar que a escola não se restringe apenas a denominação do espaço físico, mas um grupo de aparato técnico e pedagógico composta pela parte docente e discente, coordenador pedagógico, diretor, apoio pedagógico e os pais. Sem a união e trabalho de todos esses componentes a escola não teria condições de desenvolver um trabalho de qualidades.

A escola tem por objetivo estabelecer metas e concepções em consonância de uma boa proposta pedagógica, almejando uma aprendizagem significativa e adquirindo o sucesso escolar dos alunos. É importante salientar que há necessidade de os alunos são diferentes, porém, existem dois elementos os levarão possíveis aprendizagens significativas que são as habilidades e as competências. Essas habilidades e competências devem ser observadas pelos professores nos respectivos alunos, pois dessa forma reconhecerão nos educandos o cunho artístico de cada um.

Segundo Aurélio Buarque de Holanda, Arte "é a capacidade ou atividade humana de criação plástica ou musical; habilidade de representação; produção; engenho". Mediante esse fato, os Parâmetros Curriculares Nacionais (1997, p. 15), mediante a apresentação da proposta do volume das séries iniciais do Ensino Fundamental, destinado à Área Curricular Arte, ressaltou que: A educação em arte propicia o desenvolvimento do pensamento artístico, que caracteriza um modo particular de dar sentido às experiências das pessoas: por meio dele, o aluno amplia a sensibilidade, a percepção, a reflexão e a sua imaginação. 
No entanto a educação e a arte tem finalidade de oferecer ao aluno a chance de poder desenvolver seu potencial de criação artística, de produção e também de execução de suas atividades. A instituição escolar nesse momento é será considerada um elo entre o que a sociedade propaga e o desejo do educando em desenvolver suas artes baseadas na vontade, sonhos e ideais.

A comunidade escolar é o espaço das discussões sobre direitos, deveres, vida em sociedade e também das manifestações artísticas, pois, dessa forma o ensino de Arte fica completamente inserido no cotidiano do indivíduo, como é propagado nos PCNs. No ambiente escolar o aluno também aprende que existem povos, costumes, religiões, modos de produção e criação diferentes das realizadas por ele, e esses elementos faz com que o mesmo compreenda melhor o outro e passa a conviver melhor com as diferenças. Possibilitando que o indivíduo adquira uma consciência de preservação dos patrimônios culturais, ambientais e também o respeito pela diversidade.

Foi nos meados do século XX que as pessoas de destaque para o Brasil, puderam falar e produzir da acordo com suas vontades, muitos dados puderam ser trazidos para a área pedagógica, mais precisamente ao ensino da Arte pois percebeu que era de fundamental importância para o desenvolvimento da criança. Constataram também que as Artes poderiam influenciar na antropologia, filosofia, psicologia e na psicopedagogia. Dessa forma o ensino que Arte passou a ter mais importância entre os povos.

É importante ressaltar também que os princípios que valorizam o ensino das artes plásticas, da dança, da música e do teatro, denominado "Movimento da Educação através da Arte", foi fundamentada pelo filósofo inglês Herbert Riad, que deixou bem claro que esse tipo de Arte era a manifestação da "livre expressão".

Ainda no século XX, mais precisamente em 1971, a Lei de Diretrizes e Bases da Educação Nacional, LDB n ${ }^{\circ}$ 5.692, que institui o ensino profissionalizante, a Arte é incluída como Educação Artística no currículo escolar. Neste momento a arte foi vista como uma atividade educativa e não como uma matéria.

É importante salientar que a LDB, em vigência desde 1996, torna obrigatório o ensino da Arte na Educação Básica, contudo a situação, em termos de condições mínimas para que a legislação seja de fato efetivada e cumprida nas unidades escolares do país. 


\section{A PRESENÇA OU AUSÊnCIA DO PROFESSOR DE ARTE NA INSTITUICÃo ESCOLAR}

A Arte na escola vem trazendo algumas reflexões e questionamentos relacionados à atual valorização do seu ensino em sala de aula. Pois, nem sempre temos presente nas escolas uma real interlocução entre a teoria e a prática, percebe - se que essa área de conhecimento, ou seja, esta disciplina propõe algum planejamento específico. Alguns educadores estão conscientes do valor que deve ser atribuído ao ensino de Arte. Porém, observa -se, em meio a tantas indagações que este ensino sendo obrigatório por lei, está garantindo aos alunos um aprendizado significativo, e com profissionais qualificados, conforme propõe o currículo escolar.

Atualmente, apesar da presença da disciplina Arte nas instituições de ensino, percebese ainda a ausência do (a) professor (a) qualificado para este ensino. É importante salientar que muitas das vezes, esta disciplina é ministrada por pedagogos ou pelo professor de outras áreas de conhecimento, como geografia, ciências e história por exemplo. Sendo esses profissionais sem formação específica para atuarem com este ensino. Dessa forma fica a pergunta: Por que tal arbitrariedade? Subtende-se que para este campo de conhecimento não é dado a devida importância, ficando o mesmo em um patamar secundário em relação às outras disciplinas do currículo escolar.

Muitas vezes deparamos com situações vivenciadas em sala de aula que tentam garantir o ensino de Arte, mesmo sendo ministrado pela professora regente, mas ainda é precário a qualidade do ensino pois, ainda nos deparamos com a condição de pouco espaço físico para o trabalho, turmas numerosas, falta de materiais necessários, entre outros, isso muitas vezes nos faz refletir o quanto também é necessário, além da presença do professor especializado, oferecer também condições mínimas de trabalho para a efetivação do ensino de Arte com qualidade.

É muito importante conhecer como os professores regentes de turmas do ensino fundamental lidam com o ensino específico de Arte nas escolas, já que o cenário parece não ser muito favorável para a inserção deste campo de conhecimento na escola. É óbvio que não se pode generalizar, mas é certo que ainda muitos obstáculos para um ensino efetivo, que propicie também efetiva aprendizagem para os alunos. 


\section{A ARTE, UMA APRENDIZAGEM SIGNIFICATIVA: CONCEPÇÃO DE ENSINO E APRENDIZAGEM}

De acordo com a teoria de David Assube, onde o mesmo constatou que a aprendizagem seria muito mais significativa na medida fosse incorporado às estruturas de conhecimento de um aluno e o mesmo construísse significado mais amplo a partir do conhecimento prévio. David ressaltou que ao contrário disso, a aprendizagem seria mecânica ou muito repetitiva.

Percebe-se que a aprendizagem significativa tem vantagens notáveis no desenvolvimento do educando, pois é notório que se a aprendizagem trás inúmeros enriquecimento da estrutura cognitiva do indivíduo do ponto de vista da lembrança posterior e também da utilização para experimentar novas aprendizagens, garantindo deste modo, conhecimentos significativos e prazerosos por meio da descoberta e da recepção.

É importante salientar que a teoria da aprendizagem significativa possui três vantagens essências, em primeiro instante observa-se, que o conhecimento que se adquire é retido e lembrado por mais tempo. Em segundo lugar percebemos que ele também aumenta a capacidade de aprender outros materiais ou conteúdos relacionados de uma maneira mais fácil, em terceiro poderemos perceber que, uma vez esquecida a informação, a mesma poderá ser "reaprendida", para isso liza-se outro método de ensino.

A aprendizagem significativa seria como um processo central, a interação entre a estrutura cognitiva prévia do aluno e o material ou conteúdo de aprendizagem. Cool (1996) ressalta que a aprendizagem está muito ligada à funcionalidade, isto é, a possibilidade de utilizar efetivamente os conhecimentos aprendidos quando necessário, portanto, quanto maior for o grau de significatividade da aprendizagem, maior será também a sua funcionalidade.

Segundo Assube há três condições básicas necessárias para que possa haver um processo de aprendizagem significativo:

A primeira fala da significatividade lógica do novo material que é preciso aprender, remete a estrutura interna deste, que não deve ser nem arbitrária, nem confusa para facilitar o estabelecimento de relações substanciais com os conhecimentos prévios do aluno;

A segunda vem ressaltando a significatividade psicológica: para que a aprendizagem seja possível, o aluno deve dispor de uma estrutura cognitiva de conhecimentos prévios pertinentes e ativados que possa relacionar com o material que deve aprender;

Como uma terceira condição, o aluno deve ter uma determinada atitude ou disposição favorável para aprender de maneira significativa, isto é, para relacionar o que aprende com o que já sabe. 
Cool (1996, p. 235), segundo ele a última das condições comentadas para a aprendizagem significativa "é um toque de atenção sobre o papel decisivo dos aspectos motivacionais". Embora o material de aprendizagem seja potencialmente significativo, lógico e psicológico, o aluno terá uma predisposição para memorizá-lo repetitivamente, pois demanda menos esforços e é mais simples realiza-lo dessa maneira.

A aprendizagem significativa presentes nos círculos pedagógicos tem uma forte relação com a Arte, visto que, os PCNs apresentam a Arte como propiciadora do desenvolvimento do pensamento artístico e da percepção estética, que caracterizam um modo próprio de dar sentido à experiência humana, fazendo com que o aluno a amplie sua sensibilidade, percepção e também a imaginação, favorecendo o relacionamento com as outras áreas do conhecimento.

\section{CONSIDERAÇÕES FINAIS}

O presente trabalho teve por objetivo principal analisar as condições do ensino de Arte nas instituições escolares, na tentativa de compreender como os professores do Ensino Fundamental lidam com esta disciplina no contexto escolar. O mesmo buscou-se verificar se esta disciplina se equipara às demais disciplinas do currículo escolar, em relação à sua importância e se educadores têm também a compreensão da necessidade do trabalho neste campo de conhecimento.

Este estudo sobre a presença do ensino de Arte nas escolas proporcionou algumas reflexões como, por exemplo, como é importante manter essa modalidade de ensino presente em nossa sociedade, principalmente no ensino fundamental.

E no que diz respeito a trajetória de implementação e efetivação do ensino de Arte no Brasil, observa-se que houve avanços significativos, mas há ainda muito a avançar, de forma que haja maior compreensão do significado e importância dessa disciplina no currículo escolar. Ainda se faz necessário convencer professores que esse ensino não é "passatempo" ou se resume apenas em atividades para desenho livre ou para colorir, desconsiderando algum investimento mínimo na capacidade criadora dos alunos.

Faz-se necessário também repensar o currículo escolar, de forma que possam ser oferecidas metodologias e materiais adequados as atividades propostas no campo de ensino e 
aprendizagem em Arte. Como também fazer alguns ajustes emergentes e investimentos para que seja consolidado este ensino no contexto escolar, admitindo a necessidade e a importância do educador com formação acadêmica em Arte para atuar com disciplina.

Este estudo proporcionou conhecer um pouco sobre a trajetória do ensino de Arte no Brasil e refletir a respeito deste ensino foi de grande valia no sentido de ampliar a compreensão e a importância desta disciplina no currículo escolar.

\section{REFERÊNCIAS BIBLIOGRÁFICAS}

ALMEIDA, J. S. de. Mulheres na escola: Algumas reflexões sobre o magistério feminino. Cadernos de Pesquisa. São Paulo, n. 96, p. 71-78, fev., 1996.

BARBOSA, Ana Mae. Arte-educação: conflitos e acertos. São Paulo: Max Limonada, 1984.

BARBOSA, Ana Mae Tavares Bastos (Org.). Arte-educação: leitura no subsolo. 2.ed. São Paulo: Cortez, 1999.

BRASIL. Lei $\mathrm{n}^{\circ}$ 9394, de 20 de dezembro de 1996. Estabelece as diretrizes e bases da educação nacional. Brasília, Ministério da Educação e Cultura.

BRASIL, MEC/ SEB. Diretrizes Curriculares Nacionais para a Educação Infantil. Brasília: MEC/SEB, 2010.

BRASIL, MEC/SEF. Referencial Curricular Nacional para a Educação Infantil. Brasília: MEC/SEF, 1998.

BARBOSA, Ana Mae. Inquietações e Mudanças no Ensino da Arte/ Ana Mae Barbosa (org.). In: conceitos e terminologias aquecendo uma transforma - ação: Atitudes e Valores da Arte. 2ed. São Paulo: Cortez, 2003.

BARBOSA, Ana Mae Tavares Bastos (Org.). Arte-educação: leitura no subsolo. 2. ed. São Paulo: Cortez, 1999.

BERNARDES, Janaína; [et al.] ;(Uma breve história do ensino de arte no Brasil) Disponível em: <file:///C:/Users/user/Downloads/sumario2.pdf> Acesso em 15/08/2015.

CHAGAS, C.S. Arte e educação: a contribuição da arte para a educação infantil e para os anos iniciais do ensino fundamental. NET, Londrina, 2009. Disponível em:<

COLI, Jorge. O que é arte? São Paulo: Brasiliense, 2004.

COLL, César [et al.] Desenvolvimento psicológico e educação. Porto Alegre: Artes Médicas, 1996. 
